\title{
Can We Extract Production Cross-Sections from Thick Target Yield Measurements? A Case Study Using Scandium Radioisotopes
}

\author{
Mateusz Sitarz ${ }^{1,2,3, *}$, Jerzy Jastrzębski ${ }^{1}$, Férid Haddad ${ }^{3}{ }^{\oplus}$, Tomasz Matulewicz ${ }^{2}$, \\ Katarzyna Szkliniarz ${ }^{4}\left[\right.$ and Wiktor Zipper ${ }^{4}$ \\ 1 Heavy Ion Laboratory, University of Warsaw, 02-093 Warszawa, Poland; jastj@slcj.uw.edu.pl \\ 2 Faculty of Physics, University of Warsaw, 02-093 Warszawa, Poland; Tomasz.Matulewicz@fuw.edu.pl \\ 3 Groupement d'Intérêt Public ARRONAX, 44817 Saint-Herblain Cedex, France; haddad@arronax-nantes.fr \\ 4 Institute of Physics, Department of Nuclear Physics and Its Applications, University of Silesia, \\ 41-500 Chorzów, Poland; kasia.tworek@op.pl (K.S.); wiktor.zipper@us.edu.pl (W.Z.) \\ * Correspondence: msitarz@slcj.uw.edu.pl
}

Received: 27 March 2019; Accepted: 11 May 2019; Published: 14 May 2019

\begin{abstract}
In this work, we present an attempt to estimate the reaction excitation function based on the measurements of thick target yield. We fit a function to experimental data points and then use three fitting parameters to calculate the cross-section. We applied our approach to ${ }^{43} \mathrm{Ca}(\mathrm{p}, \mathrm{n})^{43} \mathrm{Sc}$, ${ }^{44} \mathrm{Ca}(\mathrm{p}, \mathrm{n}){ }^{44 \mathrm{~g}} \mathrm{Sc},{ }^{44} \mathrm{Ca}(\mathrm{p}, \mathrm{n}){ }^{44 \mathrm{~m}} \mathrm{Sc},{ }^{48} \mathrm{Ca}(\mathrm{p}, 2 \mathrm{n}){ }^{47} \mathrm{Sc}$ and ${ }^{48} \mathrm{Ca}(\mathrm{p}, \mathrm{n}){ }^{48} \mathrm{Sc}$ reactions. A general agreement was observed between the reconstructions and the available cross-section data. The algorithm described here can be used to roughly estimate cross-section values, but it requires improvements.
\end{abstract}

Keywords: medical Sc radioisotopes; radioisotope production; thick target yield measurements; cross-section reconstruction; numerical analysis

\section{Introduction}

The interest in three scandium radioisotopes, ${ }^{43} \mathrm{Sc},{ }^{44 \mathrm{~g} / \mathrm{m}} \mathrm{Sc}$ and ${ }^{47} \mathrm{Sc}$, in nuclear medicine has already been acknowledged and discussed in [1-19] (the selected properties of these radioisotopes are summarized in Table 1). Both positron emitters ${ }^{43} \mathrm{Sc}$ and ${ }^{44 \mathrm{~g}} \mathrm{Sc}$ are promising PET radioisotopes that can compete with the commonly used ${ }^{68} \mathrm{Ga}[1-5]$, while ${ }^{44 g} \mathrm{Sc}$ offers unique possibilities in the three-photon PET technique [6-8]. Additionally, ${ }^{44 \mathrm{~m}} \mathrm{Sc}$ can be used as a ${ }^{44 \mathrm{~m}} \mathrm{Sc} /{ }^{44 g} \mathrm{Sc}$ long-lived in-vivo generator as it decays mainly by a low energy transition to the ground state [9-12]. Meanwhile, ${ }^{47} \mathrm{Sc}$ is a $\beta$-emitter suitable for both therapeutic purposes and SPECT imaging [13], which is emphasized also within the IAEA Coordinated Research Project [14,15]. As mentioned in [16,17], this radioisotope is a matched pair for diagnostic ${ }^{43} \mathrm{Sc}$ and ${ }^{44 \mathrm{~g}} \mathrm{Sc}$ radioisotopes.

In our recent papers $[19,20]$, we have reported on the production routes of medical scandium radioisotopes as well as extending this data with scandium formed in natural and enriched thick $\mathrm{CaCO}_{3}$ targets (from around 50 up to $1000 \mathrm{mg} / \mathrm{cm}^{2}$ ) irradiated with $\alpha$ particles up to $30 \mathrm{MeV}$, deuterons up to $8 \mathrm{MeV}$ and protons up to $30 \mathrm{MeV}$. The thick targets were used because we found that it was not feasible to prepare thinner (in the order of $1 \mathrm{mg} / \mathrm{cm}^{2}$ ) self-supporting $\mathrm{CaCO}_{3}$ as a homogeneously thick target for our experimental set-up. The significant stopping-power of our targets allowed us to obtain experimental thick target yield (TTY) values for scandium production. 
Table 1. Nuclear data [18] of medically interesting scandium radioisotopes $\left({ }^{43} \mathrm{Sc},{ }^{44 \mathrm{~g} / \mathrm{m}} \mathrm{Sc},{ }^{47} \mathrm{Sc}\right) .{ }^{48} \mathrm{Sc}$, as a radioactive impurity, is also listed here with reference to the analysis in this paper.

\begin{tabular}{ccccc}
\hline Radio-Nuclide & $\mathbf{T}_{\mathbf{1} / \mathbf{2}}$ & Eaverage $\beta$ - or $\beta+$ & Branching or Transition & $\begin{array}{c}\text { Main } \boldsymbol{\gamma} \text {-Lines [keV] and } \\
\text { Intensities }\end{array}$ \\
\hline${ }^{43} \mathrm{Sc}$ & $3.89 \mathrm{~h}$ & $\beta+476 \mathrm{keV}$ & $\beta+88 \%$ & $373(22.5 \%)$ \\
${ }^{44} \mathrm{~g} \mathrm{Sc}$ & $3.97 \mathrm{~h}$ & $\beta+632 \mathrm{keV}$ & $\beta+95 \%$ & $1157(99.9 \%)$ \\
${ }^{44 \mathrm{~m}} \mathrm{Sc}$ & $58.61 \mathrm{~h}$ & $\mathrm{~N} / \mathrm{A}$ & $\mathrm{IT} 99 \%$ & $271(86.7 \%), 1002(1.2 \%)$, \\
${ }^{47} \mathrm{Sc}$ & $3.35 \mathrm{~d}$ & $\beta-162 \mathrm{keV}$ & $\beta-100 \%$ & $1126(1.2 \%), 1157(1.2 \%)$ \\
${ }^{48} \mathrm{Sc}$ & $43.67 \mathrm{~h}$ & $\beta-220 \mathrm{keV}$ & $\beta-100 \%$ & $159(68.3 \%)$ \\
& & & $(97.6 \%), 1213(2.4 \%), 1312(100 \%)$ \\
\hline
\end{tabular}

In this work, we want to complement our research by evaluating the ${ }^{43} \mathrm{Ca}(\mathrm{p}, \mathrm{n})^{43} \mathrm{Sc},{ }^{44} \mathrm{Ca}(\mathrm{p}, \mathrm{n})^{44 \mathrm{~g} S \mathrm{c}}$, ${ }^{44} \mathrm{Ca}(\mathrm{p}, \mathrm{n}){ }^{44 \mathrm{~m}} \mathrm{Sc},{ }^{48} \mathrm{Ca}(\mathrm{p}, 2 \mathrm{n}){ }^{47} \mathrm{Sc}$ and ${ }^{48} \mathrm{Ca}(\mathrm{p}, \mathrm{n}){ }^{48} \mathrm{Sc}$ cross-sections based on reported TTY measurements (the latter is not medically relevant, but ${ }^{48} \mathrm{Sc}$ production is important as it is a radioactive impurity). A similar attempt has already been proposed in [21] for the study of ${ }^{34 \mathrm{~m}} \mathrm{Cl}$ production. In this work, we verify this approach for above-mentioned reactions while employing a different, straight-forward numerical algorithm (our Python code is submitted in the Supplementary Materials to this paper).

\section{Materials and Methods}

In our recent work [20], we reported TTY for ${ }^{43} \mathrm{Ca}(\mathrm{p}, \mathrm{n})^{43} \mathrm{Sc}$ on ${ }^{43} \mathrm{CaCO}_{3}\left(90 \%{ }^{43} \mathrm{Ca}\right)$ targets, ${ }^{44} \mathrm{Ca}(\mathrm{p}, \mathrm{n}){ }^{44 \mathrm{~g}} \mathrm{Sc}$ and ${ }^{44} \mathrm{Ca}(\mathrm{p}, \mathrm{n}){ }^{44 \mathrm{~m}} \mathrm{Sc}$ on ${ }^{44} \mathrm{CaCO}_{3}\left(94.8 \%{ }^{44} \mathrm{Ca}\right)$ as well as ${ }^{48} \mathrm{Ca}(\mathrm{p}, 2 \mathrm{n}){ }^{47} \mathrm{Sc}$ and ${ }^{48} \mathrm{Ca}(\mathrm{p}, \mathrm{n})^{48} \mathrm{Sc}$ on ${ }^{48} \mathrm{CaCO}_{3}\left(97.1 \%{ }^{48} \mathrm{Ca}\right)$. Those TTY values are directly related to cross-sections by the following formula [22,23]:

$$
\operatorname{TTY}(E)=\frac{H N_{A}}{Z e m \tau} \int_{E_{\min }}^{E_{\max }} \frac{\sigma(E)}{\mathrm{d} E / \mathrm{d} x(E)} \mathrm{d} E
$$

where $H$ is target enrichment, $N_{A}$ is Avogadro's number, $\tau$ is the mean lifetime of a radioisotope, $\mathrm{Z}$ is the ionization number of the projectile, $e$ is the elementary charge, $m$ is the atomic mass of the target, $E_{\max }$ and $E_{\min }$ are the maximal and minimal energy of the projectile penetrating the target (in case of TTY, $E_{\min }<=$ reaction threshold), respectively, $\sigma$ is the cross-section for the nuclear reaction, and $\mathrm{d} E / \mathrm{d} x$ is the stopping-power of the projectile according to the aerial density of the target. Here, we describe the attempt to obtain the energy dependence of the cross-section (the excitation function) based on the experimental $T T Y_{\exp }(E)[\mathrm{MBq} / \mu \mathrm{Ah}]$ values for different projectile energies $E$. These data are supplemented by an assumption $\operatorname{TTY}_{\text {exp }}\left(E_{t h r}\right)=0$, where $E_{t h r}$ denotes the energy threshold for this reaction.

The crucial factor is the choice of the function used to describe the TTY energy dependence. The number of parameters of the function used to fit the data should be restricted, as the number of the experimental data points is usually limited. Therefore, we propose a simple shape,

$$
\operatorname{TTY}_{f i t}(E)=d+\frac{a c}{2}\left(\sqrt{\pi}\left(b-E_{t h r}\right) \operatorname{erf}\left\{\frac{E-b}{a}\right\}-a \exp \left\{\frac{-(E-b)^{2}}{a^{2}}\right\}\right)
$$

which fulfils several important criteria. This function is monotonically increasing, as $\operatorname{TTY}(E)$ should be. Most importantly, its derivative is a modified q-Weibull distribution [24],

$$
\left.\frac{{\mathrm{d} T T Y_{f i t}}_{\mathrm{d} E}}{\mu A h}\right]=\operatorname{MAX}\left[0 ; c\left(E-E_{t h r}\right) \exp \left\{\frac{-(E-b)^{2}}{a^{2}}\right\}\right]
$$


which reflects the global shape of the $(\mathrm{p}, \mathrm{n})$ and $(\mathrm{p}, 2 \mathrm{n})$ excitation functions, commonly used in the field of the production of medical radioisotopes. The request $T T Y_{\text {exp }}\left(E_{t h r}\right)=0$ provides the condition

$$
d=\frac{a^{2} c}{2} \exp \left\{\frac{-\left(b-E_{t h r}\right)^{2}}{a^{2}}\right\}
$$

and limits the number of $T T Y_{\text {fit }}$ parameters to 3: $a, b$ and $c$. Once those parameters are obtained, the cross-section values can be estimated as

$$
\sigma(E)[m b]=\frac{\tau[h] Z e[C] m[u]}{N_{A} H} \cdot \frac{\mathrm{d} T T Y_{f i t}}{\mathrm{~d} E}\left[\frac{M B q}{\mu A h}\right] \cdot \frac{\mathrm{d} E}{\mathrm{~d} x}\left[\frac{M e V}{m g / \mathrm{cm}^{2}}\right] \cdot 10^{42}
$$

In our case, TTY measurements were obtained on $\mathrm{CaCO}_{3}$ targets instead of metallic Ca. Therefore, we used $\mathrm{d} E / \mathrm{d} x(E)$ values corresponding to the energy loss in calcium carbonate (provided by SRIM software [25]), $m=100 \mathrm{u}$ to address the mass of $\mathrm{CaCO}_{3}$, and $\mathrm{H}$ as the level of enrichment of employed material. We have also calculated the $95 \%$ confidence band for $\operatorname{TTY}_{f i t}(E)$ fit and reconstructed the cross-section. Details of our calculations are shown and explained in the Python code attached to this paper.

Alternatively, in [21], the cross-section was reconstructed after fitting the TTY curve by calculating target yields (TY) for thicknesses corresponding to $0.1 \mathrm{MeV}$ projectile energy loss each $1 \mathrm{MeV}$ and multiplied by projectile range. This method assumes the constant stopping-power in each layer. In our approach, this simplification was not necessary.

\section{Results and Discussion}

In Figures 1-5, we show the TTY data and the reconstructed cross-sections for ${ }^{43} \mathrm{Ca}(\mathrm{p}, \mathrm{n})^{43} \mathrm{Sc}$, ${ }^{44} \mathrm{Ca}(\mathrm{p}, \mathrm{n}){ }^{44 \mathrm{~S} S \mathrm{c}},{ }^{44} \mathrm{Ca}(\mathrm{p}, \mathrm{n}){ }^{44 \mathrm{~m}} \mathrm{Sc},{ }^{48} \mathrm{Ca}(\mathrm{p}, 2 \mathrm{n}){ }^{47} \mathrm{Sc}$ and ${ }^{48} \mathrm{Ca}(\mathrm{p}, \mathrm{n}){ }^{48} \mathrm{Sc}$ reactions (the fit parameters are shown in Table 2 while the reconstructed cross-section values are listed in Table 3). We compare them with the experimental cross-section in [26-35], with the recommended values from [36], with the predictions of the EMPIRE [37] evaporation code (version 3.2.2 Malta) and with the TENDL-2017 cross-section library [38]. All reconstructions exhibit a similar shape to the model predictions and measured cross-section values, indicating the validity of modified $q$-Weibull distribution in estimating the global shape of the $(p, n)$ and $(p, 2 n)$ excitation functions.

We have also checked our reconstruction method by implementing the approach in [20]. We obtained similar values (marked on the plots) with a visible correction near the threshold in the ${ }^{44 \mathrm{~m}} \mathrm{Sc}$ case (Figure 3) but also with the discontinuity fragments due to the numerical approach. Since the mentioned paper does not provide the recommended $T T Y_{f i t}$ function, we adopted ours.

Table 2. Parameters of the $T T Y_{\text {fit }}$ (for Figures 1-5) obtained with least square method for different nuclear reactions and the $\chi 2 /$ dof values for each fit. Parameter $d$ is calculated from $a, b, c$ and $E_{t h r}$.

\begin{tabular}{cccccc}
\hline Parameter & ${ }^{43} \mathbf{C a}(\mathbf{p}, \mathbf{n}){ }^{\mathbf{4 3}} \mathbf{S c}$ & ${ }^{44} \mathbf{C a}(\mathbf{p}, \mathbf{n})^{4 \mathbf{4 9}} \mathbf{S c}$ & ${ }^{44} \mathbf{C a}(\mathbf{p}, \mathbf{n})^{44 m} \mathbf{S c}$ & ${ }^{48} \mathbf{C a}(\mathbf{p}, \mathbf{2 n})^{47} \mathbf{S c}$ & ${ }^{48} \mathbf{C a}(\mathbf{p}, \mathbf{n})^{\mathbf{4 8}} \mathbf{S c}$ \\
\hline$E_{\text {thr }}[\mathrm{MeV}]$ & 3.07 & 4.54 & 4.81 & 8.93 & theory: 0.51 \\
$a[\mathrm{MeV}]$ & $10(2)$ & $8.8(6)$ & $13.7(7)$ & $14.7(9)$ & adopted: 3.0 \\
$b[\mathrm{MeV}]$ & $4.5(6)$ & $4.8(1.0)$ & $7.0(1)$ & $9.05(14)$ & $4.0(8)$ \\
$c\left[\mathrm{MBq}(\mu \mathrm{Ah})^{-1}(\mathrm{MeV})^{-2}\right]$ & $7.1(9)$ & $24.5(1.2)$ & $0.075(3)$ & $1.57(6)$ & $2.5(2)$ \\
$d[\mathrm{MBq} / \mu \mathrm{Ah}]$ & 348 & 952 & 6.82 & 169 & 79.4 \\
$\chi 2 / \mathrm{dof}$ & 1.30 & 0.57 & 6.11 & 1.05 & 1.79 \\
\hline
\end{tabular}

In the case of ${ }^{43} \mathrm{Sc}$ data (Figure 1), the recent experimental results [34] are significantly lower than other measurements (by a factor of 2 around $10 \mathrm{MeV}$ proton energy). The experimental results for TTY are quite linear in the measured proton energy range and do not reach the expected saturation, so the resulting excitation function is relatively flat and does not reproduce any of the previous measurements. 
This reaction might require further validation, as with the extension of TTY measurements up to $30 \mathrm{MeV}$ proton energy.

A general agreement is observed for ${ }^{44 \mathrm{~g}} \mathrm{Sc}$ (Figure 2), both with the theoretical models and experimental results, although again the data by [34] are lower than the measurements. More discrepancies are observed in the case of ${ }^{44 \mathrm{~m}} \mathrm{Sc}$ (Figure 3). The excitation function obtained from TTY measurements does not show the peak seen in the experiments and in model calculations and overestimates the values near the reaction threshold. We suspect that the problem with this reconstruction might be related to the offset of TTY data, as only in case of ${ }^{44 \mathrm{~m}} \mathrm{Sc}$ are the TTY values below model predictions at low energies and above them at higher energies, which causes the reconstructed excitation function to be flatter.

For ${ }^{47} \mathrm{Sc}$ (Figure 4), the shape of the reconstruction reflects the shape predicted by both model calculations. While our results provide about $10 \%$ lower values compared to the models, recent measurements [35] indicate similar values at low energies but about $20 \%$ higher values at maximum.

Finally, we decided to adopt the arbitrary value of $E_{t h r}=3.0 \mathrm{MeV}$ as a parameter for ${ }^{48} \mathrm{Sc}$ fit (Figure 5) to satisfy the visible and significant TTY build-up at this energy rather than the actual threshold $(0.51 \mathrm{MeV})$. This might be explained by the fact that the shape of the function used for the fit does not adequately describe the behavior of the cross-section at energies much below the Coulomb barrier. Since the cross-section values far below the Coulomb barrier are very small, they do not contribute significantly to the TTY values. The extracted cross-section values are in line with the data in [30] at lower energies and in [35] at higher energies.
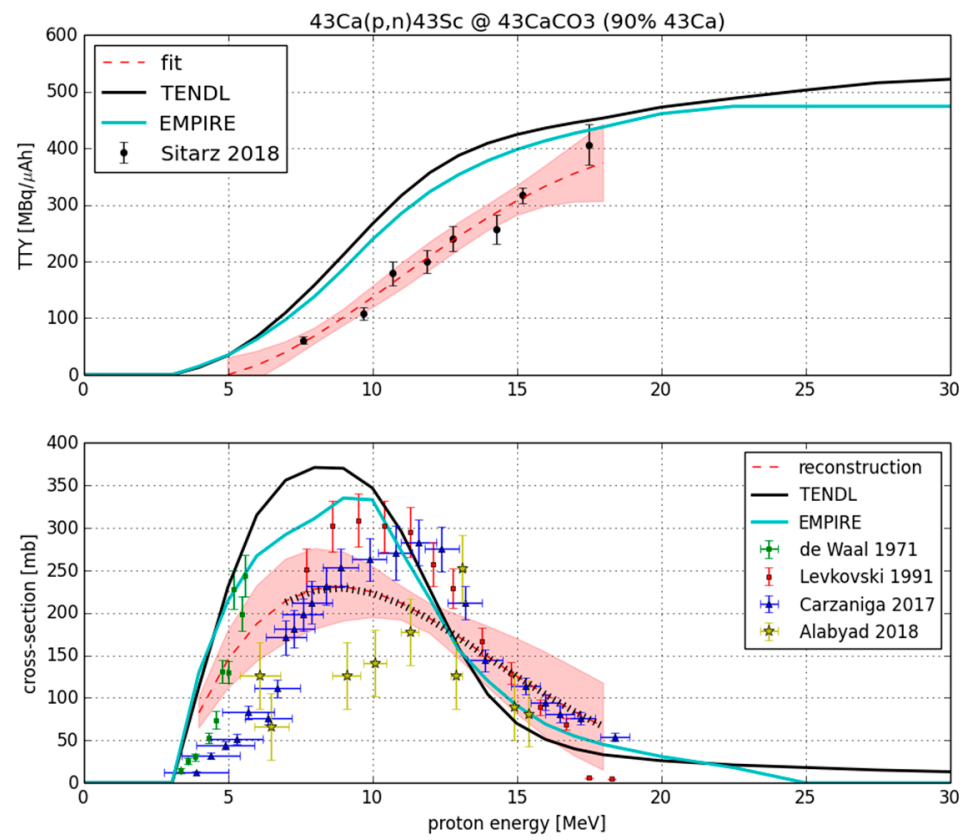

Figure 1. Reconstruction of ${ }^{43} \mathrm{Ca}(\mathrm{p}, \mathrm{n})^{43} \mathrm{Sc}$ cross-section (bottom) based on the fit to TTY data on ${ }^{43} \mathrm{CaCO}_{3}$ enriched in $90 \%{ }^{43} \mathrm{Ca}$ (top). The cross-section data points are taken from $[26,31,33,34]$. 

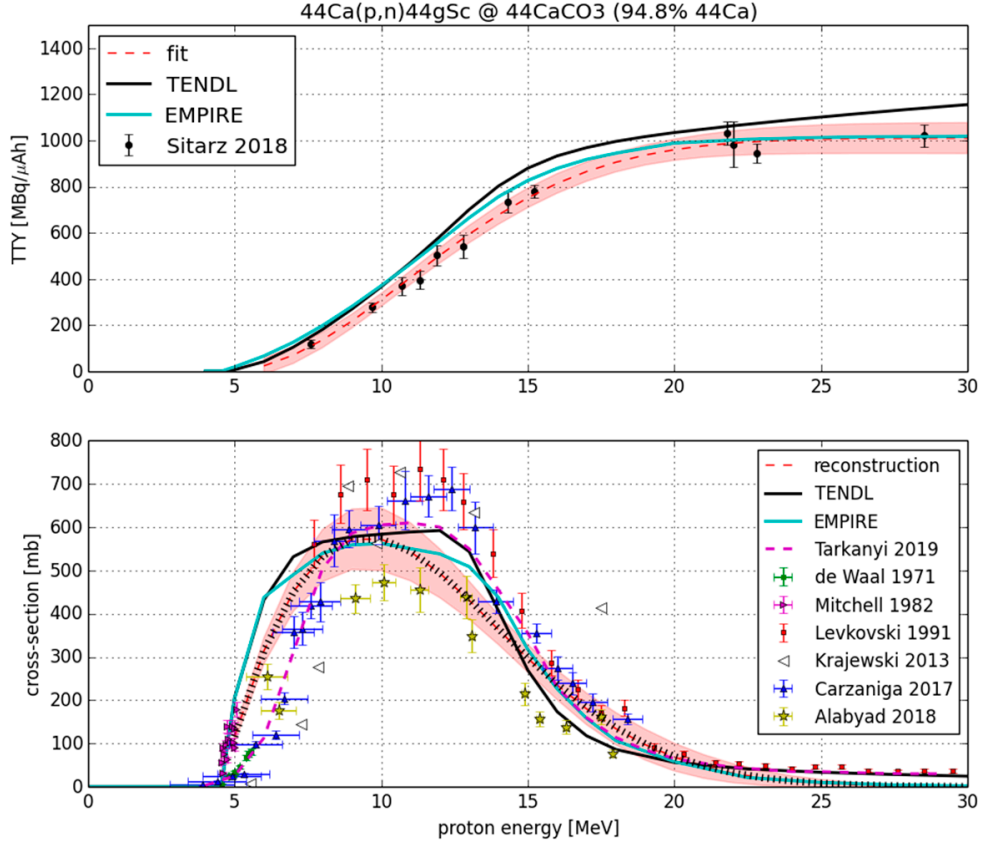

Figure 2. Reconstruction of ${ }^{44} \mathrm{Ca}(\mathrm{p}, \mathrm{n})^{44 \mathrm{~g}} \mathrm{Sc}$ cross-section (bottom) based on the fit to TTY data on ${ }^{44} \mathrm{CaCO}_{3}$ enriched in $94.8 \%{ }^{44} \mathrm{Ca}$ (top). The cross-section data points are taken from $[26,29,31-34,36]$.
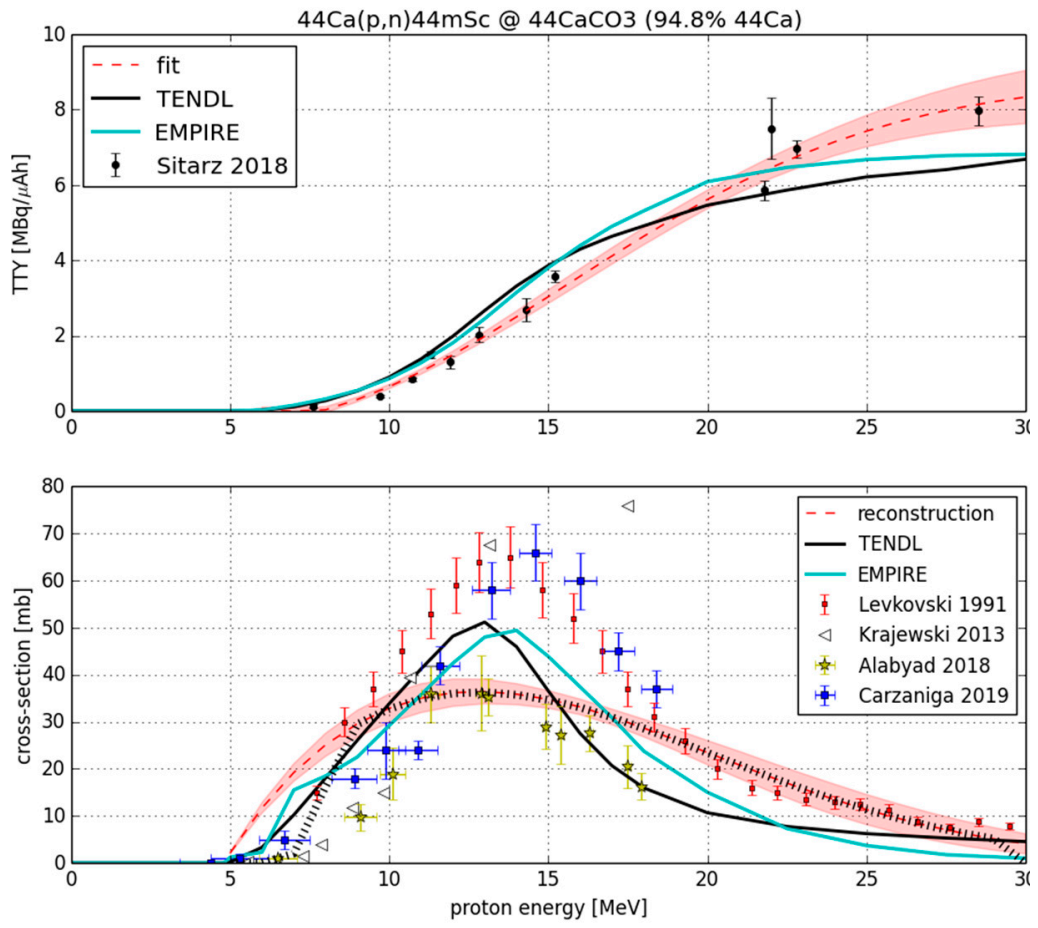

Figure 3. Reconstruction of ${ }^{44} \mathrm{Ca}(\mathrm{p}, \mathrm{n})^{44 \mathrm{~m}} \mathrm{Sc}$ cross-section (bottom) based on the fit to TTY data on ${ }^{44} \mathrm{CaCO}_{3}$ enriched in $94.8 \%{ }^{44} \mathrm{Ca}$ (top). The cross-section data points are taken from [31,32,34,35]. 

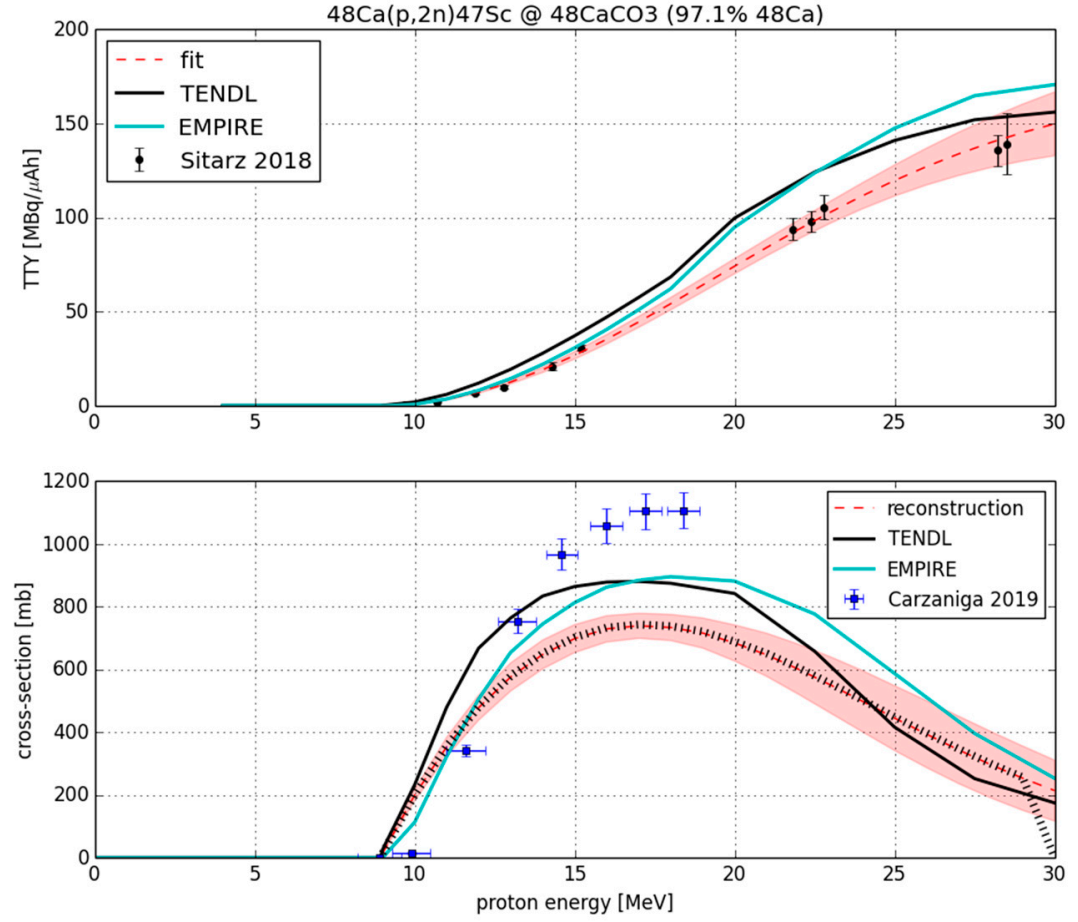

Figure 4. Reconstruction of ${ }^{48} \mathrm{Ca}(\mathrm{p}, 2 \mathrm{n}){ }^{47} \mathrm{Sc}$ cross-section (bottom) based on the fit to TTY data on ${ }^{48} \mathrm{CaCO}_{3}$ enriched in $97.1 \%{ }^{48} \mathrm{Ca}$ (top). The cross-section data points are taken from [35].
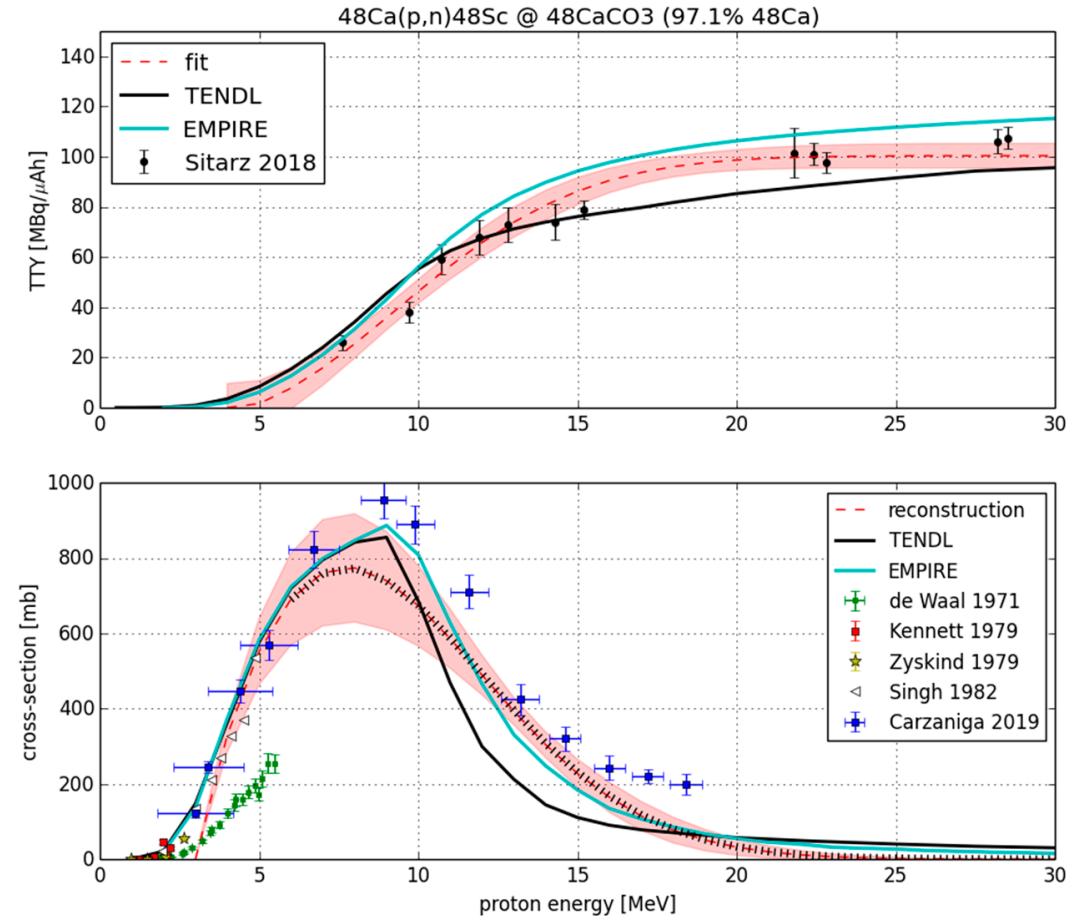

Figure 5. Reconstruction of ${ }^{48} \mathrm{Ca}(\mathrm{p}, \mathrm{n})^{48} \mathrm{Sc}$ cross-section (bottom) based on the fit to TTY data on ${ }^{48} \mathrm{CaCO}_{3}$ enriched in $97.1 \%{ }^{48} \mathrm{Ca}$ (top). Here, we adopted an arbitrary threshold of $3 \mathrm{MeV}$. The cross-section data points are taken from $[26-28,30,35]$. The results from $[27,28,30]$ are averaged. 
Table 3. Cross-section values for different nuclear reactions deduced from the thick target yield data from [20].

\begin{tabular}{cccccc}
\hline \multirow{2}{*}{ E [MeV] } & \multicolumn{5}{c}{$\boldsymbol{\sigma}[\mathbf{m b}]$} \\
\cline { 2 - 5 } & ${ }^{\mathbf{4 3}} \mathbf{C a}(\mathbf{p}, \mathbf{n})^{\mathbf{4 3}} \mathbf{S c}$ & ${ }^{\mathbf{4 4}} \mathbf{C a}(\mathbf{p}, \mathbf{n})^{\mathbf{4 4} \mathbf{g} \mathbf{S c}}$ & ${ }^{\mathbf{4 4}} \mathbf{C a}(\mathbf{p}, \mathbf{n})^{\mathbf{4 4 m} \mathbf{S c}}$ & ${ }^{\mathbf{4 8}} \mathbf{C a}\left(\mathbf{p}, \mathbf{2 n} \mathbf{4}^{\mathbf{4 7}} \mathbf{S c}\right.$ & ${ }^{\mathbf{4 8}} \mathbf{C a}(\mathbf{p}, \mathbf{n})^{\mathbf{4 8}} \mathbf{S c}$ \\
\hline 5 & $145(20)$ & $115(6)$ & $2.11(8)$ & 0 & $552(48)$ \\
6 & $187(26)$ & $314(13)$ & $11.7(5)$ & 0 & $692(66)$ \\
7 & $214(29)$ & $450(20)$ & $19.2(8)$ & 0 & $761(77)$ \\
8 & $228(28)$ & $534(26)$ & $25.1(1.1)$ & 0 & $744(78)$ \\
9 & $231(24)$ & $572(31)$ & $29.6(1.3)$ & $14.2(6)$ & $740(71)$ \\
10 & $225(18)$ & $572(32)$ & $32.9(1.4)$ & $199(7)$ & $674(58)$ \\
11 & $211(12)$ & $543(30)$ & $35.0(1.4)$ & $353(14)$ & $586(43)$ \\
12 & $193(10)$ & $493(25)$ & $36.2(1.3)$ & $478(18)$ & $490(29)$ \\
13 & $172(15)$ & $431(19)$ & $36.4(1.2)$ & $576(20)$ & $393(20)$ \\
14 & $148(21)$ & $363(15)$ & $35.9(1.0)$ & $647(20)$ & $304(18)$ \\
15 & $125(26)$ & $297(14)$ & $34.7(8)$ & $698(20)$ & $228(21)$ \\
16 & $104(29)$ & $235(15)$ & $33.1(7)$ & $729(19)$ & $164(22)$ \\
17 & $84(30)$ & $180(16)$ & $31.0(7)$ & $739(18)$ & $115(21)$ \\
18 & $66(30)$ & $134(16)$ & $28.7(8)$ & $734(18)$ & $78(19)$ \\
19 & & $97(16)$ & $26.1(1.0)$ & $716(21)$ & $51(15)$ \\
20 & & $68(14)$ & $23.4(1.1)$ & $684(26)$ & $32(12)$ \\
21 & & $47(12)$ & $20.8(1.3)$ & $647(31)$ & $20(9)$ \\
22 & & $31(10)$ & $18.2(1.4)$ & $600(35)$ & $12(6)$ \\
23 & & $20(7)$ & $15.7(1.4)$ & $550(40)$ & $7(4)$ \\
24 & & $13(6)$ & $13.5(1.4)$ & $499(43)$ & $4(3)$ \\
25 & & $8(4)$ & $11.3(1.4)$ & $445(46)$ & $2.0(1.6)$ \\
26 & & $5(3)$ & $9.5(1.4)$ & $393(47)$ & $1.0(9)$ \\
27 & & $7.8(1.3)$ & $343(48)$ & $0.5(5)$ \\
28 & & $6.4(1.2)$ & $297(47)$ & $0.3(3)$ \\
29 & & $5.1 .8)$ & $4.0(9)$ & $253(45)$ & $0.12(16)$ \\
30 & & $0.8(7)$ & $213(43)$ & $0.05(8)$ \\
\hline
\end{tabular}

\section{Conclusions and Summary}

We have presented an attempted numerical method for cross-section evaluation based on the thick target yield (TTY) measurements obtained from the irradiation of thick targets (in which the energy of a projectile is reduced to the reaction threshold). This method is based on fitting a function with three free parameters to TTY data points and using its analytical derivative to obtain the cross-section. The fitting requires the knowledge of the reaction threshold and a sufficient number of experimental points to represent the shape of the TTY curve, including the saturation region.

Using this approach, we were able to obtain a useful estimation of cross-sections for the production of medically important ${ }^{43} \mathrm{Sc},{ }^{44 \mathrm{~g}} \mathrm{Sc},{ }^{44 \mathrm{~m}} \mathrm{Sc},{ }^{47} \mathrm{Sc}$, and ${ }^{48} \mathrm{Sc}$ radioisotopes via $(\mathrm{p}, \mathrm{n})$ and $(\mathrm{p}, 2 \mathrm{n})$ reactions on $\mathrm{Ca}$. The results were compared to the already measured cross-sections and to the model predictions. General agreement is observed; however, not all experimental results confirm our reconstructions, particularly those near the reaction threshold. In conclusion, our algorithm can provide good insights for the $(\mathrm{p}, \mathrm{xn})$ excitation function, but improvements are necessary.

Supplementary Materials: The following are available online at http://www.mdpi.com/2410-390X/3/2/29/s1.

Author Contributions: M.S.: formal analysis, software, methodology, writing-original draft, writing—review \& editing; J.J.: conceptualization; F.H.: supervision, writing-review \& editing; T.M.: conceptualization, methodology, supervision, writing — review \& editing; K.S.: supervision, writing-review \& editing; W.Z.: conceptualization, supervision, writing-review \& editing.

Funding: Part of this work was performed within the framework of the EU Horizon 2020 project RIA-ENSAR2 (654 002). This research was also partly supported by the Polish Funding Agency NCBiR grant No. DZP/PBS3/2319/2014 and by a grant from the French National Agency for Research called "Investissements d'Avenir", Equipex Arronax-Plus noANR-11-EQPX-0004, Labex IRON noANR-11-LABX-18-01, and ISITE NEXT no. ANR-16-IDEX-0007. 
Acknowledgments: The authors sincerely thank Anna Stolarz and Agnieszka Trzcińska (from Heavy Ion Laboratory, Warsaw) as well as Aleksander Bilewicz (from Institute of Nuclear Chemistry and Technology, Warsaw) for valuable discussions and constructive suggestions regarding this work. The PhD cotutelle scholarship from the French Government for Mateusz Sitarz is acknowledged.

Conflicts of Interest: The authors declare no conflict of interest.

\section{References}

1. Koumarianou, E.; Pawlak, D.; Korsak, A.; Mikolajczak, R. Comparison of receptor affinity of ${ }^{\text {nat }}$ Sc-DOTA-TATE

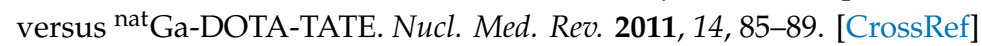

2. Walczak, R.; Krajewski, S.; Szkliniarz, K.; Sitarz, M.; Abbas, K.; Choiński, J.; Jakubowski, A.; Jastrzębski, J.; Majkowska, A.; Simonelli, F.; et al. Cyclotron production of ${ }^{43} \mathrm{Sc}$ for PET imaging. EJNMMI Phys. 2015. [CrossRef] [PubMed]

3. Bunka, M.; Müller, C.; Vermeulen, C.; Haller, S.; Türler, A.; Schibli, R.; van der Meulen, N.P. Imaging quality of ${ }^{44} \mathrm{Sc}$ in comparison with five other PET radionuclides using Derenzo phantoms and preclinical PET. Appl. Radiat. Isot. 2016, 110, 129-133. [CrossRef] [PubMed]

4. $\quad$ Domnanich, K.A.; Müller, C.; Farkas, R.; Schmid, R.M.; Ponsard, B.; Schibli, R.; Türler, A.; van der Meulen, N.P. ${ }^{44} \mathrm{Sc}$ for labeling of DOTA- and NODAGA-functionalized peptides: Preclinical in vitro and in vivo investigations. EJNMMI Radiopharm. Chem. 2016. [CrossRef]

5. Domnanich, K.A.; Eichler, R.; Müller, C.; Jordi, S.; Yakusheva, V.; Braccini, S.; Behe, M.; Schibli, R.; Türler, A.; van der Meulen, N.P. Production and separation of ${ }^{43} \mathrm{Sc}$ for radiopharmaceutical purposes. EJNMMI Radiopharm. Chem. 2017. [CrossRef] [PubMed]

6. Grignon, C.; Barbet, J.; Bardiès, M.; Carlier, T.; Chatal, J.F.; Couturier, O.; Cussonneau, J.P.; Faivre, A.; Ferrer, L.; Girault, S.; et al. Nuclear medical imaging using $\beta+\gamma$ coincidence from ${ }^{44}$ Sc radio-nuclide with liquid xenon as detection medium. Nucl. Instrum. Meth. A 2017, 571, 142-145. [CrossRef]

7. Lang, C.; Habs, D.; Parodi, K.; Thirolf, P.G. Sub-millimeter nuclear medical imaging with reduced dose application in positron emission tomography using $\beta+\gamma$ coincidences. JINST 2013, 9, P01008. [CrossRef]

8. Thirolf, P.G.; Lang, C.; Parodi, K. Perspectives for Highly-Sensitive PET-Based Medical Imaging Using $\beta+\gamma$ Coincidences. Acta Phys. Pol. A 2015, 127, 1441-1444. [CrossRef]

9. Huclier-Markai, S.; Kerdjoudj, R.; Alliot, C.; Bonraisin, A.C.; Michel, N.; Haddad, F.; Barbet, J. Optimization of reaction conditions for the radiolabeling of DOTA and DOTA-peptide with ${ }^{44 \mathrm{~m} / 44} \mathrm{Sc}$ and experimental evidence of the feasibility of an in vivo PET generator. Nucl. Med. Biol. 2014, 41, e36-e43. [CrossRef] [PubMed]

10. Alliot, C.; Audouin, N.; Barbet, J.; Bonraisin, A.C.; Bossé, V.; Bourdeau, C.; Bourgeois, M.; Duchemin, C.; Guertin, A.; Haddad, F.; et al. Is there an interest to use deuteron beams to produce non-conventional radionuclides? Front. Med. 2015. [CrossRef]

11. Alliot, C.; Kerdjoudj, R.; Michel, N.; Haddad, F.; Huclier-Markai, S. Cyclotron production of high purity ${ }^{44 \mathrm{~m}, 44} \mathrm{Sc}$ with deuterons from ${ }^{44} \mathrm{CaCO}_{3}$ targets. Nucl. Med. Biol. 2015, 42, 524-529. [CrossRef]

12. Duchemin, C.; Guertin, A.; Haddad, F.; Michel, N.; Métivier, V. Production of scandium- $44 \mathrm{~m}$ and scandium-44g with deuterons on calcium-44: Cross-section measurements and production yield calculations. Phys. Med. Biol. 2015, 60, 17. [CrossRef]

13. Domnanich, K.A.; Müller, C.; Benešová, M.; Dressler, R.; Haller, S.; Köster, U.; Ponsard, B.; Schibli, R.; Türler, A.; van der Meulen, N.P. ${ }^{47} \mathrm{Sc}$ as useful $\beta$ - emitter for the radiotheragnostic paradigm: A comparative study of feasible production routes. EJNMMI Radiopharm. Chem. 2017. [CrossRef]

14. International Atomic Energy Agency. Call for Coordinated Research Project “Therapeutic Radiopharmaceuticals Labelled with New Emerging Radionuclides $\left({ }^{67} \mathrm{Cu},{ }^{186} \mathrm{Re}\right.$, ${ }^{47}$ Sc)". 2015. Available online: https://www.iaea.org/projects/crp/f22053 (accessed on 13 May 2019).

15. International Atomic Energy Agency. 2015. Available online: http://cra.iaea.org/cra/stories/2015-09-30F22053-New_Emerging_Radionuclides.html (accessed on 13 May 2019).

16. Müller, C.; Bunka, M.; Haller, S.; Köster, U.; Groehn, V.; Bernhardt, P.; van der Meulen, N.P.; Türler, A.; Schibli, R. Promising Prospects for ${ }^{44}$ Sc- $/{ }^{47}$ Sc-Based Theragnostics: Application of ${ }^{47}$ Sc for Radionuclide Tumor Therapy in Mice. J. Nucl. Med. 2014, 55, 1658-1664. [CrossRef] 
17. Müller, C.; Domnanich, K.A.; Umbricht, C.A.; van der Meulen, N.P. Scandium and terbium radionuclides for radiotheranostics: Current state of development towards clinical application. Br. J. Radiol. 2018. [CrossRef]

18. International Atomic Energy Agency. Live Chart of Nuclides. Available online: https://www-nds.iaea.org/ relnsd/vcharthtml/VChartHTML.html (accessed on 12 May 2019).

19. Szkliniarz, K.; Sitarz, M.; Walczak, R.; Jastrzębski, J.; Bilewicz, A.; Choiński, J.; Jakubowski, A.; Majkowska, A.; Stolarz, A.; Trzcińska, A.; Zipper, W. Production of medical Sc radioisotopes with an alpha particle beam. Appl. Radiat. Isot. 2016, 118, 182-189. [CrossRef]

20. Sitarz, M.; Szkliniarz, K.; Jastrzębski, J.; Choiński, J.; Guertin, A.; Haddad, F.; Jakubowski, A.; Kapinos, K.; Kisieliński, M.; Majkowska, A.; et al. Production of Sc medical radioisotopes with proton and deuteron beams. Appl. Radiat. Isot. 2018, 142, 104-112. [CrossRef]

21. Nagatsu, K.; Fukumura, T.; Takei, M.; Szelecsényi, F.; Kovács, Z.; Suzuki, K. Measurement of thick target yields of the ${ }^{\text {nat }} \mathrm{S}(\alpha, \mathrm{x})^{34 \mathrm{~m}} \mathrm{Cl}$ nuclear reaction and estimation of its excitation function up to $70 \mathrm{MeV}$. Nucl. Inst. Meth. Phys. Res. B 2008, 266, 709-713. [CrossRef]

22. Phelps, M.E. PET: Molecular Imaging and Its Biological Applications; Springer: New York, NY, USA, 2004.

23. Pedroso de Lima, J.J. Nuclear Medicine Physics Series in Medical Physics and Biomedical Engineering, Cyclotron and Radionuclide Production, Series in Medical and Biomedical Engineering; CRC Press: Boca Raton, FL, USA, 2010.

24. Jose, K.K.; Naik, S.R. On the q-Weibull Distribution and Its Applications. Com. Stat. Th. Meth. 2009, 38, 912-926. [CrossRef]

25. Ziegler, J.F.; Ziegler, M.D.; Biersack, J.P. SRIM Code, Version 2008.04. Available online: http://www.srim.org/ (accessed on 12 May 2019).

26. de Waal, T.J.; Peisach, M.; Pretorius, R. Activation cross sections for proton-induced reactions on calcium isotopes up to $5.6 \mathrm{MeV}$. J. Inorg. Nucl. Chem. 1971, 33, 2783-2789. [CrossRef]

27. Kennett, S.R.; Switkowski, Z.E.; Paine, B.M.; Sargood, D.G. Yield Measurements in the Reactions ${ }^{48} \mathrm{Ca}(\mathrm{p}, \gamma){ }^{49} \mathrm{Sc}$ and ${ }^{48} \mathrm{Ca}(\mathrm{p}, \mathrm{n}){ }^{48}$ Sc. J. Phys. G 1979, 5, 399. [CrossRef]

28. Zyskind, J.L.; Davidson, J.M.; Esat, M.T.; Spear, R.H.; Shapiro, M.H.; Fowler, W.A.; Barnes, C.A. Cross Section Measurements and Thermonuclear Reaction Rates for ${ }^{48} \mathrm{Ca}(\mathrm{p}, \gamma){ }^{49} \mathrm{Sc}$ and ${ }^{48} \mathrm{Ca}(\mathrm{p}, \mathrm{n})^{48} \mathrm{Sc}$. Nucl. Phys. A 1979, 315, 430-444. [CrossRef]

29. Mitchell, L.W.; Anderson, M.R.; Kennett, S.R.; Sargood, D.G. Cross-sections and thermonuclear reaction rates for ${ }^{42} \mathrm{Ca}(\mathrm{p}, \gamma){ }^{43} \mathrm{Sc},{ }^{44} \mathrm{Ca}(\mathrm{p}, \gamma){ }^{45} \mathrm{Sc},{ }^{44} \mathrm{Ca}(\mathrm{p}, \mathrm{n}){ }^{44} \mathrm{Sc}$ and ${ }^{45} \mathrm{Sc}(\mathrm{p}, \mathrm{n}){ }^{45} \mathrm{Ti}$. J. Nucl. Phys. A 1982, 380, 318-334. [CrossRef]

30. Singh, G.; Kailas, S.; Saini, S.; Chatterjee, A.; Balakrishnan, M.; Mehta, M.K. Reaction ${ }^{48} \mathrm{Ca}(\mathrm{p}, \mathrm{n})^{48} \mathrm{Sc}$ from E(p) $=1.885$ to $5.1 \mathrm{MeV}$. Pramana 1982, 19, 565-577. [CrossRef]

31. Levkovskij, V.N. Cross-section of medium mass nuclide activation $(A=40-100)$ by medium energy protons and alpha-particles ( $E=10-50 \mathrm{MeV}$ ); Inter-Vesi: Moscow, Russia, 1991.

32. Krajewski, S.; Cydzik, I.; Abbas, K.; Bulgheroni, A.; Simonelli, F.; Holzwarth, U.; Bilewicz, A. Cyclotron production of ${ }^{44} \mathrm{Sc}$ for clinical application. J. Radiochim. Acta 2013. [CrossRef]

33. Carzaniga, T.S.; Auger, M.; Braccini, S.; Bunka, M.; Ereditato, A.; Nesteruk, K.P.; Scampoli, P.; Türler, A.; van der Meulen, N. Measurement of ${ }^{43} \mathrm{Sc}$ and ${ }^{44} \mathrm{Sc}$ production cross-section with an $18 \mathrm{MeV}$ medical PET cyclotron. Appl. Radiat. Isot. 2017, 129, 96-102. [CrossRef] [PubMed]

34. Alabyad, M.; Mohamed, G.V.; Hassan, H.E.; Takács, S.; Ditrói, F. Experimental measurement and theoretical calculations for proton, deuteron and $\alpha$-particle induced nuclear reactions on calcium: Special relevance to the production of ${ }^{43,44}$ Sc. J. Radioan. Nucl. Chem. 2018, 316, 119-128. [CrossRef]

35. Carzaniga, T.S.; Braccini, S. Cross-section measurement of ${ }^{44 \mathrm{~m}} \mathrm{Sc}_{\mathrm{c}}{ }^{47} \mathrm{Sc},{ }^{48} \mathrm{Sc}$ and ${ }^{47} \mathrm{Ca}$ for an optimized ${ }^{47} \mathrm{Sc}$ production with an $18 \mathrm{MeV}$ medical PET cyclotron. Appl. Radiat. Isot. 2019, 143, 18-23. [CrossRef]

36. Tárkányi, F.T.; Ignatyuk, A.V.; Hermanne, A.; Capote, R.; Carlson, B.V.; Engle, J.W.; Kellett, M.A.; Kibédi, T.; Kim, G.N.; Kondev, F.G.; et al. Recommended nuclear data for medical radioisotope production: diagnostic positron emitters. J. Radioan. Nucl. Chem 2019, 319, 533-666. [CrossRef] 
37. Herman, M.; Capote, R.; Carlson, B.V.; Obložinský, P.; Sin, M.; Trkov, A.; Wienke, H.; Zerkin, V. EMPIRE: Nuclear Reaction Model Code System for Data Evaluation. Nucl. Data Sheets 2007, 108, 2655-2715. [CrossRef]

38. Koning, A.J.; Rochman, D. Modern Nuclear Data Evaluation with The TALYS Code System. Nucl. Data Sheets 2012, 113, 2841-2934. [CrossRef]

(C) 2019 by the authors. Licensee MDPI, Basel, Switzerland. This article is an open access article distributed under the terms and conditions of the Creative Commons Attribution (CC BY) license (http://creativecommons.org/licenses/by/4.0/). 